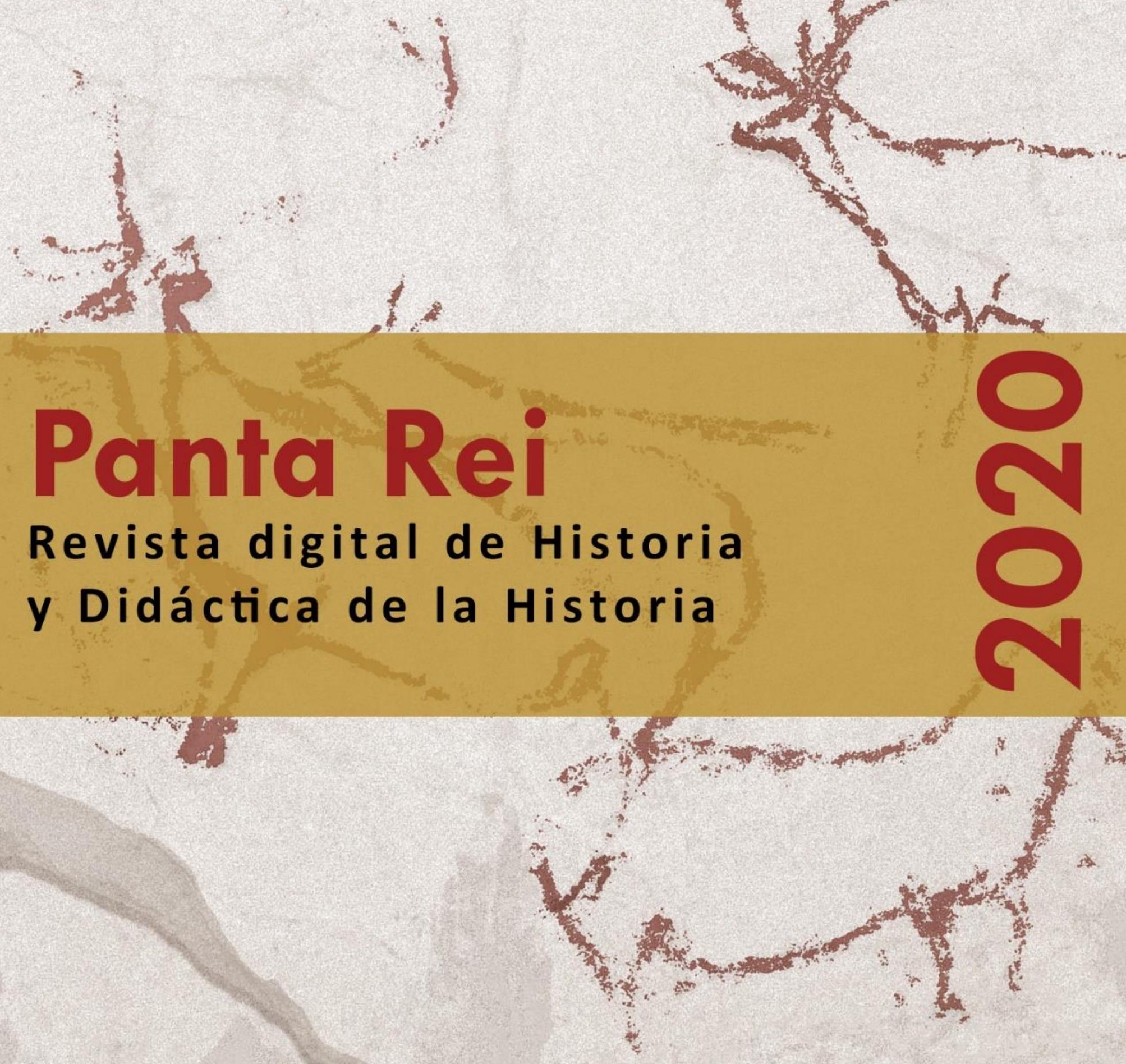




\section{0}

Revista anual

Fecha de inicio: 1995

RevistaPantaRei.pantarei@um.es

\section{Edita:}

Centro de Estudios del Próximo Oriente y la

Antigüedad Tardía - CEPOAT

Edificio Universitario Saavedra Fajardo.

Universidad de Murcia

C/ Actor Isidoro Máiquez, 9

30007 - MURCIA - ESPAÑA

Teléfono: $(+34) 868883890$

cepoat@um.es

Web: www.um.es/cepoat/pantarei

Ediciones de la Universidad de Murcia - EDITUM

Edificio Pleiades. Campus de Espinardo.

Universidad de Murcia

$\mathrm{C} /$ Campus, s/n

30100 - MURCIA - ESPAÑA

Teléfono: $(+34) 868883013$

En portada: calco de las pinturas rupestres de la editum@um.es

Web: https://www.um.es/web/editum/

Cueva del Niño. García Moreno et al., 2016.

Edición 2020

ISSNe: 2386-8864

Responsables de los textos: sus autores.

ISSN: $1136-2464$

Depósito legal: MU-966-1995

Responsable de la presente edición: Consejo Editorial de Panta Rei. 


\section{CONSEJO DE REDACCIÓN}

Coordinador editorial

Egea Vivancos, Alejandro [Didáctica de las Ciencias Sociales, Universidad de Murcia]

Secretaria

Arias Ferrer, Laura [Didáctica de las Ciencias

Sociales, Universidad de Murcia]

Editores

Jiménez Vialás, Helena [Historia Antigua, Universidad de Murcia]

Martínez Gil, Tània [Didáctica de las Ciencias

Sociales, Universidad de Barcelona]

Meseguer Gil, Antonio José [Historiador, Profesor de

Secundaria]

Ortiz García, Jónatan [Arqueología, Universidad de

Alcalá de Henares]

Romero Molero, Alberto [Arqueología, Universidad

Isabel I]

Sáez Giménez, David Omar [Historiador, Profesor

de Secundaria]

Sáez Rosenkranz, Isidora V. [Didáctica de las

Ciencias Sociales, Universidad de Barcelona]

Sánchez Mondejar, Celso Miguel [Arqueólogo,

Patrimonio Inteligente]

Responsable informático

Martínez García, José Javier [CEPOAT, Universidad de Murcia]

Responsables de traducción y corrección lingüística Martínez Martínez, Cristina [Profesora de Secundaria, Sociedad Española de Lenguas Modernas] Albaladejo Albaladejo, Sara [ISEN-Universidad de Murcia]

\section{CONSEJO ASESOR}

Adroher Auroux, Andrés María [Arqueología, Universidad de Granada]

Albero Muñoz, $M^{a}$ del Mar [H. ${ }^{a}$ del Arte, Universidad de Murcia]

Alia Miranda, Francisco [Historia Contemporánea, UCLM]

Arciniega García, Luis [Historia del Arte, Universidad de Valencia]

Barrio Barrio, Juan Antonio [Historia Medieval,

Universidad de Alicante]

Castellano i Solé, Núria [Egiptología, Schola

Didàctica Activa S.L.]

Chapman, Arthur [History Education, University

College of London, Reino Unido]

Cid López, Rosa María [Historia Antigua, Universidad de Oviedo]

Cobacho López, Ángel [Derecho, Universidad de Murcia]

Cuenca López, José María [Didáctica de las Ciencias Sociales, Universidad de Huelva]
Egea Bruno, Pedro M. ${ }^{a}$ [Historia Contemporánea, Universidad de Murcia]

Feijoo Martínez, Santiago [Arqueología, Consorcio

Ciudad Monumental de Mérida]

García Atienzar, Gabriel [Prehistoria, Universidad de

Alicante]

Ginestí Rosell, Anna [Filología Clásica, Katholische

Universität Eichstätt-Ingolstadt]

González Monfort, Neus [Didáctica de las

Ciencias Sociales, Universidad Autónoma de

Barcelona]

González Soutelo, Silvia [Arqueología, Universidad de Vigo]

Haber Uriarte, María [Prehistoria, Universidad de Murcia]

Hernández de la Fuente, David [Filología Clásica, Universidad Complutense]

Hutson, Scott R. [Anthropology, University of Kentucky, EEUU]

Igual Luis, David [Historia Medieval, UCLM]

Irigoyen López, Antonio [Historia Moderna,

Universidad de Murcia]

Jover Maestre, Francisco Javier [Prehistoria,

Universidad de Alicante]

Mahony, Simon [Digital Humanities, University College of London, Reino Unido]

Marsilla de Pascual, Francisco Reyes [Técnicas

historiográficas, Universidad de Murcia]

Martínez-Burgos García, Palma [H. ${ }^{a}$ del Arte, UCLM]

Mathis, Christian [Didaktik der Geschichte, PH Zürich]

Miralles Maldonado, José Carlos [Filología Clásica,

Universidad de Murcia]

Molina Gómez, José Antonio [Historia Antigua,

Universidad de Murcia]

Mónica Ghirardi [Historia Moderna, Universidad

Nacional de Córdoba, Argentina]

Navarro Espinach, Germán [Historia Medieval,

Universidad de Zaragoza]

Noguera Celdrán, José Miguel [Arqueología,

Universidad de Murcia]

Ortiz Heras, Manuel [Historia Contemporánea, UCLM]

Panzram, Sabine [Historia Antigua, Universität

Hamburg]

Pérez Molina, Miguel Emilio [Filología Clásica,

Universidad de Murcia]

Prados Martínez, Fernando [Arqueología,

Universidad de Alicante]

Sánchez lbáñez, Raquel [Didáctica de las Ciencias

Sociales, Universidad de Murcia]

Sancho Gómez, Miguel Pablo [Educación, UCAM]

Victoria Moreno, Diego [Historia Contemporánea,

UNED]

Vilar García, María José [Historia Contemporánea,

Universidad de Murcia]

Vivas Sainz, Inmaculada [H. ${ }^{a}$ del Arte, UNED]

Zamora López, José Ángel [Próximo Oriente Antiguo,

CCHS-CSIC] 



\section{Índice}

\section{Artículos}

Las ocupaciones paleolíticas en el sur de la provincia de Albacete

Noelia Sánchez Martínez

El elefante en las acuñaciones hispanocartaginesas

José Luis Aledo Martínez

La epigrafía votiva romana de Caldas de Montbui (Vallés Oriental, Barcelona) (ss. I-II d. C.). Un ejemplo de promoción de las élites provinciales de la tarraconensis en centros de aguas mineromedicinales

Jesús Sánchez Alguacil

Representación de la historia de España por medio de la filatelia. Estudio de los sellos diseñados por Gallego y Rey

Pedro Vázquez-Miraz

La representación del patrimonio arqueológico en los libros de texto de Educación Primaria: EI 109 contexto indígena canario como estudio de caso

A. José Farrujía, Carmen Ascanio Sánchez, Ulises Martín Herández y Cristo Manuel Hernández Gómez

La empatía como elemento para la adquisición del pensamiento histórico en alumnos de 129 bachillerato. Un estudio de caso centrado en la Guerra Civil española y el franquismo Sebastián Molina Puche y Adrián Salmerón Ayala

Fuentes orales para el desarrollo de la empatía histórica: un estudio en la formación del 155 profesorado de Educación Infantil

$M^{a}$. Teresa Carril-Merino, Beatriz Andreu-Mediero, Mercedes de la Calle Carrecedo y Esther López Torres

¿Qué aporta el género a la formación de docentes de historia? La valoración de la perspectiva de género entre los estudiantes del Máster de Profesor/Profesora en Educación Secundaria Helena Rausell Guillot

Educar para una ciudadanía crítica: una investigación a partir de los usos y finalidades de la historia escolar

Néstor Banderas Navarro

\section{Reseñas}

A. Brilli (2018). El viaje a Oriente, Madrid: A. Machado Libros, 390 págs Juan Álvarez García

Altamira (Hugh Hudson, 2016) 



\title{
El elefante en las acuñaciones hispanocartaginesas
}

\section{The Elephant in the Hispano-Carthaginian Minting}

\author{
José Luis Aledo Martínez \\ Universitat Oberta de Catalunya \\ joseluisalemar96@gmail.com \\ (iD) 0000-0002-8179-2390
}

Recibido: 19/12/2019

Aceptado: 01/04/2020

\begin{abstract}
Resumen
Uno de los temas más discutidos por la historiografía del mundo antiguo, tanto pasada como presente, es la influencia helenística en la ciudad norteafricana de Cartago. En particular, se ha generado un intenso debate en torno a la numismática de la familia Bárquida como una evidencia de que sus políticas eran una imitación de los reinos griegos del Mediterráneo oriental, entre otros aspectos por la inclusión del elefante en sus reversos. Por nuestra parte, a través de un análisis iconográfico del elefante en la numismática helenística valoraremos los elementos de continuidad y ruptura en el caso Bárquida, para matizar los prejuicios y mitos surgidos a partir de las corrientes historiográficas. Basándonos en ello, podemos hablar de una adaptación de la ideología del poder griega a los modelos púnicos de Occidente.
\end{abstract}

\section{Palabras clave}

Influencias culturales, Historiografía, Cultura africana, Historia antigua, Numismática.

\begin{abstract}
One of the most discussed topics in historiography of the ancient world, both past and present, is the Hellenistic influence in the North African city of Carthage. In particular, an intense debate has arisen around the numismatics of the Barcid family as evidence that their policies were an imitation of the Greek kingdoms of the Eastern Mediterranean, among other things because of the inclusion of the elephant in their reverses. For our part, through an iconographic analysis of the elephant in Hellenistic numismatics, we will assess the elements of continuity and rupture in the Barcid case to qualify the prejudices and myths that emerged from historiographic trends. Based on this, we can speak of an adaptation of the Greek ideology of power to the Punic models of the West.
\end{abstract}

\section{Keywords}

Cultural Influences, Archaeology, Historiography, African Culture, Ancient History, Numismatics. 


\section{Introducción}

El historiador, como todo profesional dedicado a la ciencia, es hijo de su tiempo, lo que implica, para bien y para mal, tener que asumir los prejuicios pasados y presentes que todo individuo arrastra inherentemente. Una aproximación a la historia de Cartago en siglo III a. C. presenta esa problemática, dado que nos enfrentamos a la ardua tarea de tratar con el máximo rigor posible el peso que ejerce en la república norteafricana la cultura helenística forjada en el Mediterráneo oriental. Esto resulta especialmente problemático en la "provincia" de lberia", cuyos gobernadores, los carismáticos Bárquidas, protagonizan el intenso debate acerca de la inclusión de la cultura helenística en la idiosincrasia púnica de Occidente.

La historiografía, tanto española como extranjera, permanece divida en esta cuestión, dado que encontramos un sector que considera que las viejas tesis del "reino Bárquida de lberia" (Blázquez, 1976 , p. 44.) pueden ser matizadas y reorientadas hacía un proceso de cambio cultural propio de una fase tardía del helenismo, denominada por algunos "helenistización" (Bendala Galán, 2015 , p. 14). Esta corriente, que podríamos considerar como "aperturista", acepta que los rostros masculinos que aparecen en la numismática hispanocartaginesa sean retratos de los gobernadores Bárquidas, siguiendo los patrones de los soberanos helenísticos (García-Bellido, 2019). Por el contrario, el sector más "autárquico", defiende que no es posible considerar que Cartago, a nivel general, forme parte de la órbita helenística, ni que los Bárquidas, a nivel particular, introduzcan en la Península lbérica la cultura helenística (Ferrer Albelda, 2011). Ello entra en relación con los partidarios de que las representaciones antropomórficas de las series hispanas son rostros de deidades como Melqart/Heracles (Villaronga, 1973).

Por nuestra parte, a pesar de que, inevitablemente, tomamos partido por la primera corriente, consideramos que ambas tendencias, aunque diferentes, no son excluyentes, dado que presentan una justificación basada en la metodología histórica, no obstante, consideramos que es posible proyectar una tercera vía derivada de la visión del historiador francés Jacques Alexandropoulos, el cual contrapone la dualidad que se dio entre la iconografía numismática de Cartago, fiel a su tradición semita, y de lberia, definible como "púnico-helenística" durante el gobierno Bárquida (2002). La coexistencia de ambos modelos merece un análisis profundo a través de la iconografía púnico-helenística, cuyo emblema más característico es el elefante, dado que este elemento ha pasado prácticamente desapercibido a la comunidad científica, que ha preferido aunar esfuerzos en torno a la problemática de los retratos.

La inclusión de los paquidermos como elemento iconográfico entra en relación con el tópico decimonónico que asociaba a Cartago, y más concretamente a Aníbal, con entidades "orientales" (Jiménez Vialás, 2012, pp. 511-512), lo cual derivó en una especie de morbus asiaticus que intentaba convertir al general cartaginés en un rey helenístico amparándose en el hecho, que por otra parte se convirtió en su imagen arquetípica, de que gran parte de sus tácticas militares incluyesen el empleo de contingentes de elefantes como elemento de choque. De hecho, encontramos ejemplos en la historiografía del siglo XX en los que se llegó a afirmar que los cartagineses usaban elefantes indios (Berthelot, 1936), así como que el elefante era un animal totémico de los Bárquidas (Lancel, 1995). Ambos ejemplos, aunque separados por más de medio

1 Con respecto al debate entre hegemonía o imperialismo a la hora de definir el poder ejercido por Cartago en Iberia, véase Whittaker, 1978; López Castro, 1991; González Wagner, 1999; Ferrer Albelda, 2002-2003; Hoyos, 2010; Barceló, 2019. 
siglo, confirman esa concepción orientalizante del elefante asociado a la figura del general cartaginés.

En función de todo lo expuesto, este artículo pretende ofrecer una nueva visión de la iconografía helenística de la numismática hispanocartaginesa, con el elefante como caso de estudio. Para ello, se introducirá de manera breve el origen de esta simbología en el Mediterráneo oriental en el siglo IV a. C., así como unas nociones acerca de la relación de Cartago con el mundo helenístico, para concluir con la lberia púnica. Para poder facilitar la comprensión de la iconografía, hemos considerado hacer un breve comentario de determinadas figuras incluidas en el texto. El resultado de este análisis quedará reflejado en las oportunas valoraciones surgidas a lo largo del trabajo.

\section{El elefante en la iconografía postalejandrina}

Tras la muerte de Alejandro III de Macedonia, conquistador del Imperio Aqueménida, asistimos a un turbulento período de crisis política y territorial en el que sus antiguos compañeros de armas, ahora sátrapas del reino, pugnarán por hacerse con el poder: las llamadas guerras de los Diádocos. A pesar de que desde un punto de vista geopolítico es un período apasionante en el que se desarrollan conflictos, en algunos casos simultáneamente, desde el Egeo hasta el Indo (Bosworth, 2002), no podemos perder de vista la guerra propagandística que emprenden determinados sátrapas, especialmente Ptolomeo en Egipto y Seleuco en Mesopotamia, para legitimar sus aspiraciones políticas a través de la figura de Alejandro y la asociación con ciertos animales, especialmente el elefante, que había sido introducido en los ejércitos griegos tras la campaña de la India (Scullard, 1974).

\subsection{La búsqueda de la legitimidad a través de las exuviae elephantis}

Durante sus primeros años como gobernador de Egipto, Ptolomeo, amigo de la infancia de Alejandro (Arri., An., III, 6, 5), comenzó a batir unas acuñaciones en cuyo reverso aparecía la efigie de Alejandro con un tocado de elefante, de manera similar a la leonté empleada por este para simbolizar su relación genealógica con Heracles, unos cuernos de carnero y una piel de serpiente (Figura 1). A través de esta iconografía tripartita, elefante, carnero y serpiente, buscaba legitimar la continuidad dinástica a ojos de los egipcios y los macedonios. Los cuernos de carnero simbolizarían a la deidad libia, Amón, mientras que la égida a Zeus (van Oppen de Ruitier, 2019). El caso de las exuviae elephantis es más complejo, dado que existen varias interpretaciones. Por una parte, podría tratarse de una metonimia de la India (Trautman, 2015), es decir, el elefante expuesto como un despojo representaría las victorias de Alejandro en suelo indio. Por otra parte, podría ser un elemento que corroborase la vinculación con el dios Dioniso (Goukoski, 1981), de manera similar a como los monarcas argéadas hicieron con Heracles al representarlo con la piel del león de Nemea (King, 2018), en tanto que ambos habían regresado triunfantes de la India con elefantes (DS., III, 65, 7). 


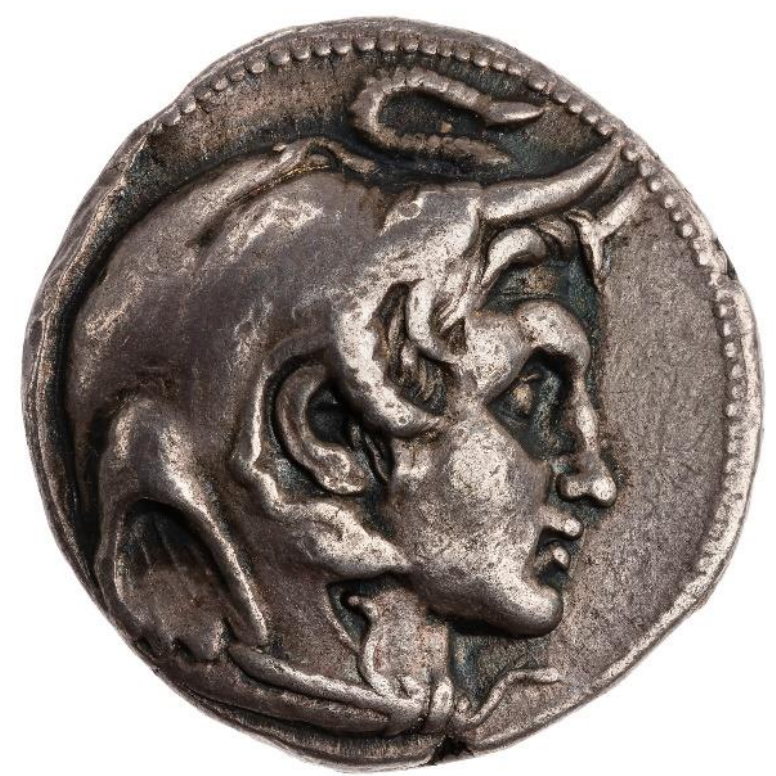

Figura 1. Anverso de un tetradracma de plata $(17,1$ g.) en el que se representa a Alejandro III de Macedonia con tocado de elefante, acuñado por el sátrapa de Egipto Ptolomeo (317-311 a. C.). Fuente: American Numismatic Society (1944.100.35702).

Unas décadas después, Seleuco I, rey de Siria, copiará esta iconografía -con la cual debía de estar familiarizado, dado que residió unos años en Egipto al servicio de Ptolomeo (DS., XIX, 56)adaptándola a sus intereses. Entre los años 300-298 a. C., Seleuco batió unas series en oro que seguían el patrón persa en las que se representaba a Alejandro con las exuviae elephantis (Figura 2), prescindiendo de la iconografía regional egipcia (Erikson, 2019). Podemos contextualizar estas series, limitadas a las satrapías orientales, como una conmemoración del "triunfo" de Seleuco frente al rey indio Chandragupta, gracias al cual obtuvo un gran número de elefantes, a cambio de renunciar a los territorios fronterizos con la India (Kosmin, 2014). Mediante este recurso simbólico, Seleuco transmitía una continuidad entre las distintas campañas en la India.

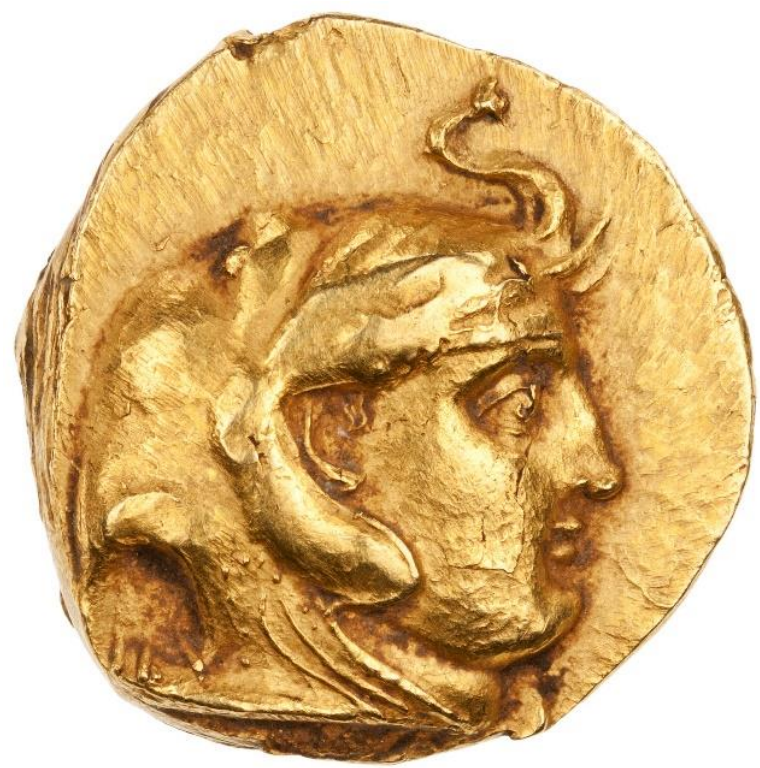

Figura 2. Anverso de un dárico de oro (8,35 g.) en el que se representa a Alejandro III de Macedonia con tocado de elefante, acuñado por Seleuco I en Babilonia (300-298 a. C.). Fuente: American Numismatic Society (1960.176.42). 


\subsection{El rey como comandante de los elefantes}

El tránsito del siglo IV al III a.C. viene marcado por una nueva concepción de la ideología del poder y la zoología, tanto en Oriente como en Occidente. En el Artha-shastra (2.2.13), tratado indio sobre el buen gobierno, escrito por el consejero del rey Chandragupta, se recoge que el elefante es el principal valedor de la victoria del rey. Esta asociación del monarca victorioso con el elefante aparece también, en fechas similares, en Grecia, dado que tras la batalla de Ipso

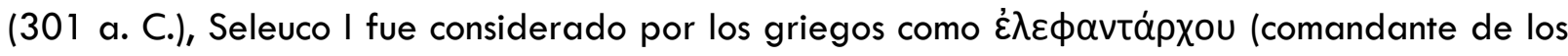
elefantes) (Plu., Demetr., 25, 4). La imagen del paquidermo deja de ser exclusivamente una

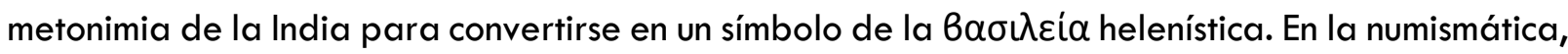
Seleuco introduce al elefante sin más atributos, como bien ilustra la Figura 3, como manifestación visual de su fuerza de choque (Alonso Troncoso, 2013).

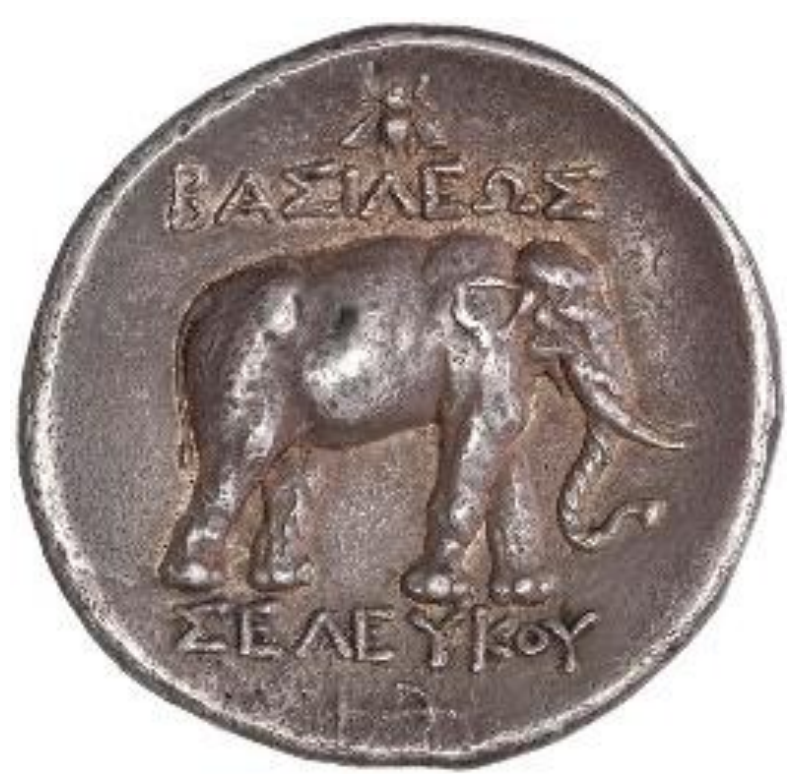

Figura 3. Reverso de un tetradracma de plata $(16,75$ g.) en el que se representa a un elefante indio y una abeja, acuñado por Seleuco I en Pérgamo (281 a. C.). Leyenda: BA $\Sigma I \Lambda E \Omega \Sigma \Sigma E \wedge E Y K O Y$ ("del rey Seleuco"). Fuente: American Numismatic Society (1967.152.675).

La figura central es un elefante indio (Elephas Maximus), cuyas características más notorias son su lomo cóncavo y sus orejas pequeñas. Aparece representado de perfil con el fin de resaltar su anatomía, sin elementos ornamentales. Esta representación sobria buscaba equiparar la figura del soberano con este poderoso espécimen, o al menos a eso induce la colocación de la titulatura sobre él. En la parte superior de la leyenda $B A \Sigma I \Lambda E \Omega \Sigma$ aparece una abeja, representación zoológica del dios Apolo (hHom., h.Merc., 550-561). A su vez, bajo el nombre del rey aparece un ancla, emblema de la dinastía que conectaba al soberano con el dios a través de una profecía (App., Syr., 56). La confluencia de la iconografía sacra con la militar representaba la doble naturaleza del soberano, protegido por los dioses y vencedor en las batallas.

\subsection{La contra ofensiva occidental}

Las representación del elefante en el siglo IV a. C., tal y como hemos expuesto, presenta una evolución según los intereses políticos y la gestación de una nueva concepción del poder regio. Pasamos de una representación como despojo a la exaltación de su majestuosidad. No obstante, la entrada en el siglo III a. C. dio paso a la traslación de esta iconografía hacía el Mediterráneo 
occidental, a pesar de que contamos con la excepción de Agatocles de Siracusa, que tras su proclamación como rey copió la iconografía ptolemaica de las exuviae elephantis (Dahmen, 2007). La traslación de la geopolítica hacía el Mediterráneo central, con la intervención de Pirro en Italia y Sicilia, permitió introducir la simbología del elefante en las potencias occidentales: Roma y Cartago.

Los romanos se apropiarán de esta asociación del monarca con el elefante para hacer una contraofensiva propagandística tras la expulsión de Pirro de Italia. Buena muestra de ello son los platos cerámicos pintados procedentes de las necrópolis de Capena (Figura 4a) y Aleria (Figura 4b), que nos ofrecen datos acerca del equipo que portaban los elefantes. Es muy posible que fuesen parte de la producción realizada por la República romana para festejar el triunfo de Curio Denato tras la batalla de Benevento en el 275 a. C. (Flor., Epit., I. 13.28).
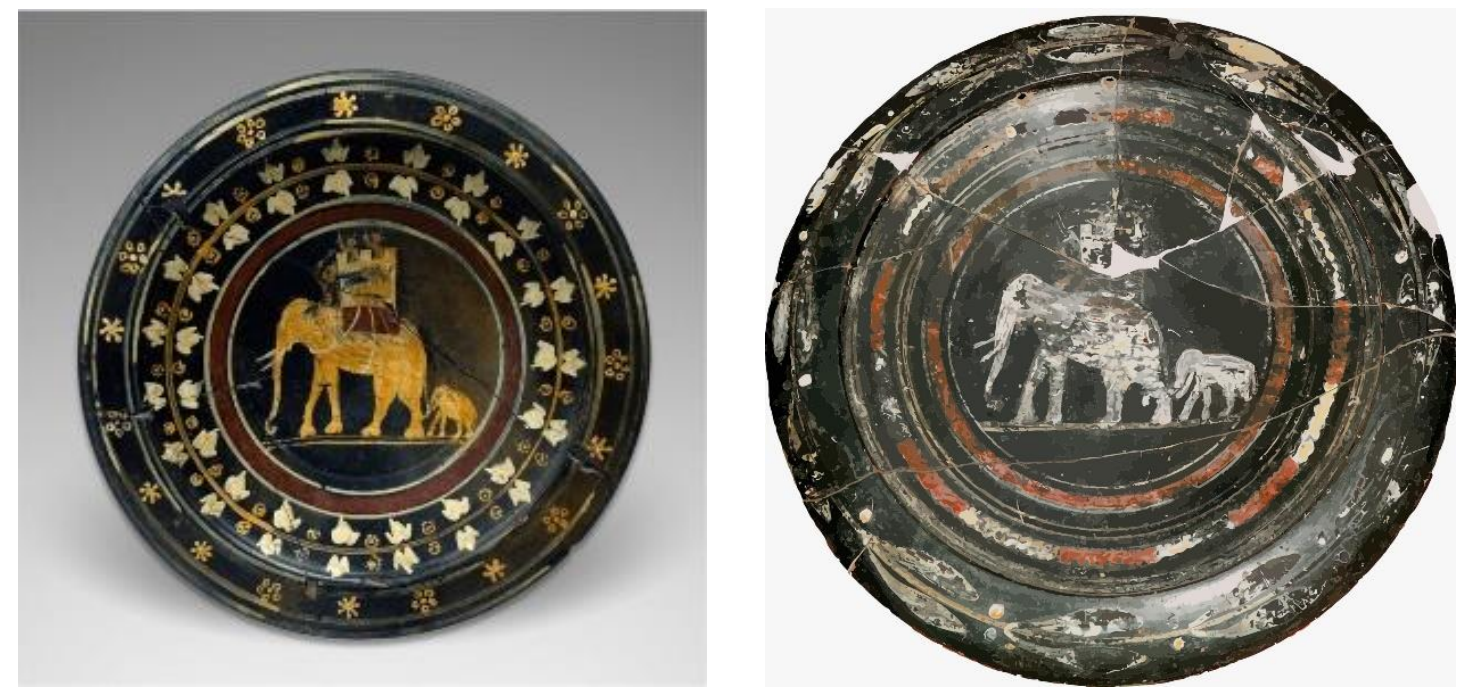

Figura 4. A) Plato cerámico policromado procedente de la tumba 233 de la necrópolis etrusca Le Macchie en Capena. Fuente: Museo Nazionale Etrusco "Villa Giulia" de Roma (no. inv. 23.949). B) Plato cerámico policromado procedente de la necrópolis corsa de Aleria. Museo Departamental de Arqueología Ghijlormu Carcopino. Fuente: Jehasse y Jehasse, 1973, p. 99. Siglo III a. C. Ambos casos representan a dos elefantes indios (un adulto y una cría), portando el adulto un cornaca y una torre sobre la que van dos soldados.

Estas producciones muestran a dos elefantes indios desfilando, a pesar de que se puede diferenciar una especie adulta y una cría, focalizaremos nuestro análisis sobre la primera. Ambas piezas son excepcionales, a pesar de su diferente estado de conservación, dado que nos permiten analizar todos los elementos que forman el equipamiento del elefante de guerra helenístico. Es interesante diferenciar entre la herencia india y las novedades griegas. Dentro de esta segunda categoría entra la torre, que al parecer es introducida por Pirro (Plu., Pyrrh., XXXII, 2), desde la que dos soldados lanzaban armas arrojadizas contra los enemigos. Las fuentes ofrecen visiones diferentes acerca del equipo de la torre. Por una parte, Eliano (NA., XIII, 9) afirma que las torres se colocan sobre la grupa desnuda. Por otra parte, Plutarco (Eum., 14, 8), a pesar de que su contextualización no es fiable (Scullard, 1974), defiende que bajo las torres se colocaban mantos.

Nuestros casos de análisis parecen corroborar la segunda versión, ya que se representa un manto bajo la torre, muy posiblemente para evitar que el elefante fuese herido por los proyectiles enemigos, o como un elemento de adorno que buscase intimidar al enemigo. Asimismo, estas piezas presentan características similares a las phalerae de plata grecobactrianas (Figura 5) del siglo II a. C. (Pfrommer, 1993). Un análisis comparativo nos hace pensar que el origen de los 
soldados sería diferente según su cometido, puesto que en la pieza oriental se aprecia, gracias al tratamiento individualizado de los rostros y los ropajes, que los soldados de la torre serían griegos, mientras que el cornaca sería indio. La phalera también incluye un manto bajo la torre. Un elemento común a todas las representaciones es que los cornacas portan una aguijada (Arist., MA., 610a).

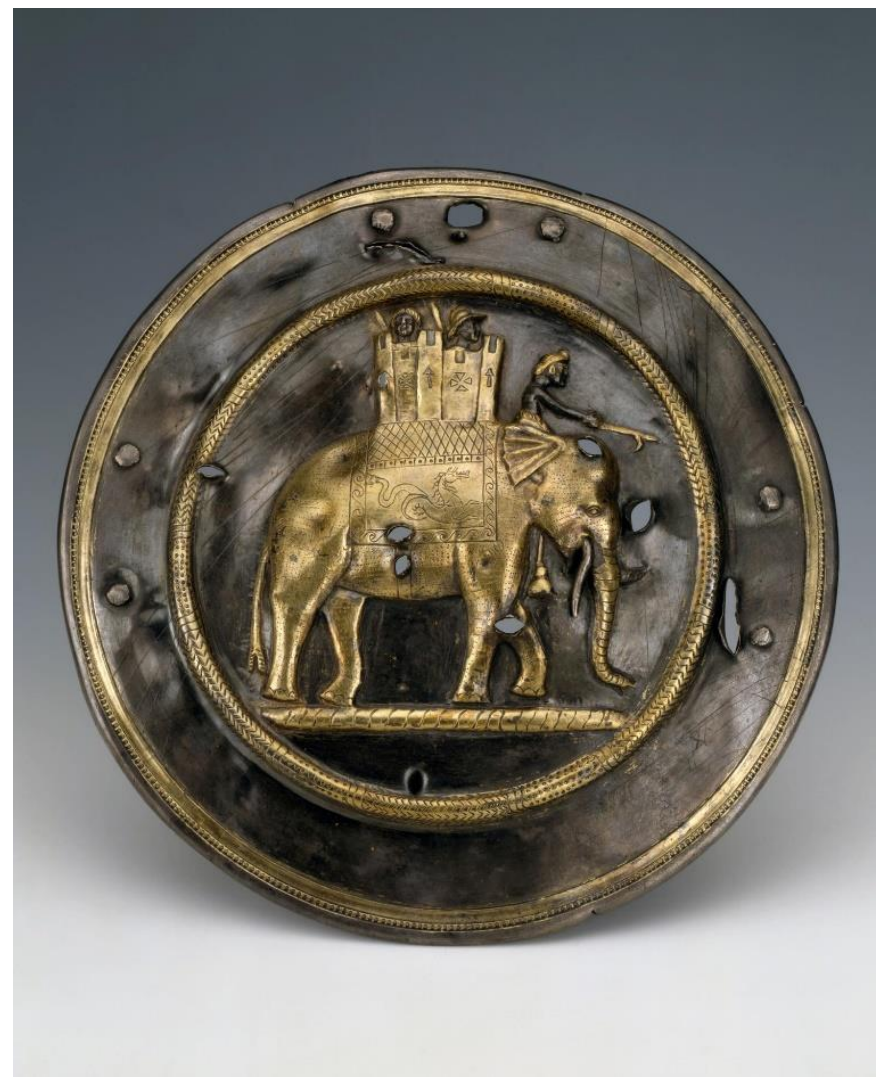

Figura 5. Phalera de plata en la que se representa a un elefante indio equipado con una torre sobre la que se ha colocado un manto que representa a un tritón. Siglo II a. C. Fuente: Hermitage Museum (S-65).

\section{La problemática "helenización" de Cartago}

En las páginas iniciales de este trabajo aludíamos a un debate historiográfico candente en la actualidad, la influencia de la cultura helenística en Cartago. Un punto de partida, que nunca está de mal recordar, es que, a pesar de su fuerte tradición semítica, la ciudad norteafricana se encontraba en una privilegiada ubicación, siendo un puerto de escala entre lo que llamamos Mediterráneo "occidental" y "oriental". Me sirvo del entrecomillado no de forma inocente, dado que a la hora de abordar una aproximación histórica solemos servirnos de dichos términos para hablar de dos realidades, dos mundos diferentes, donde no sabemos muy bien el lugar que le corresponde a Cartago. Sería interesante plantearse la siguiente cuestión zqué es la helenización?

Al igual que otras denominaciones para etapas históricas, "helenismo" es un término creado a posteriori, en este caso por el historiador alemán del siglo XIX Johann Gustav Droysen, y que engloba el tiempo histórico transcurrido entre Alejandro III de Macedonia y la anexión romana de Egipto. Una de las claves del concepto, cuya finalidad es más didáctica que práctica, es dar cobertura a una "nueva era" marcada por la fusión entre Oriente y Occidente, tras la conquista del Imperio Aqueménida y la gestación de los reinos griegos de Oriente. La principal 
problemática de esta definición es su carácter geográfico, a grandes rasgos los territorios comprendidos entre el Mar Egeo y el río Indo (Thonemann, 2016). Para ejemplificar esta problemática nos serviremos de un texto de época romana:

Octavio y Antonio se repartieron de nuevo entre sí todo el imperio de los romanos, se estableció como límite la ciudad iliria de Escodra, que se suponía estaba situada en medio del golfo Adriático; todas las provincias e islas al Este de esta isla y hasta el río Éufrates pertenecerían a Antonio, y las que quedaban al Oeste hasta el océano corresponderían a Octavio (App., BC., 5, 65).

Aunque la sola contextualización del fragmento expuesto nos permitiría verter ríos de tinta acerca de la concepción geopolítica de Occidente y Oriente, queremos, en esta ocasión, solamente destacar un punto, lliria como frontera. Concepciones de este tipo, el mundo griego a partir de la Hélade, explican esta delimitación geográfica de lo helénico. Hace ya dos décadas, Langher (2000) relacionaba la diplomacia de Agatocles de Siracusa con los reyes griegos del Mediterráneo oriental con la búsqueda de una alianza entre los griegos orientales y occidentales para poner freno al expansionismo cartaginés en Sicilia. La interpretación de una diferencia entre griegos orientales y occidentales demuestra esa alteridad entre ambos "mundos griegos".

A raíz de esta problemática conceptual, creemos oportuno hacer una breve reflexión de corte historiográfico. Tal y como se ha expuesto, el concepto helenización, acuñado en el siglo XIX, comienza a ser insuficiente para englobar la materialidad histórica de un mundo en constante movimiento y que no se constriñe a un espacio geográfico concreto. En este punto, la comunidad científica ha considerado oportuno buscar nuevas alternativas conceptuales (Bonnet, 2014), entre las que podríamos destacar la rompedora "helenistización" (Bendala Galán, 2015, p. 14), dado que responde a ese vacío historiográfico.

\subsection{Rasgos de la cultura helenística en Cartago}

La ciudad de Cartago, a pesar de su origen fenicio y por tanto no griego, parte con este condicionante geográfico, que la sitúa dentro de un supuesto helenismo occidental (Purcell, 2013). Sin embargo, a pesar de que nunca renunció a su tradición oriental, como consecuencia de su interacción continuada en Sicilia, sobre todo a partir del siglo IV a. C., momento en que se intensificaron los conflictos militares para afianzar la eparquía púnica (García Coca, 2012), encontramos una serie de aspectos que evidencian la aceptación de la cultura griega en Cartago. Buena prueba de ello es el decreto emitido por el Senado prohibiendo a sus ciudadanos aprender a hablar o escribir griego, a raíz de una derrota frente a Dioniso I (lust., XX, 5,13-14), lo cual evidencia, así como el hecho de que Aníbal tuviese años después dos profesores griegos (Nep., Han., XIII), que un sector de la aristocracia estaba interesado en dominar la lengua helena.

A diferencia de lo que ocurre en las monarquías helenísticas, donde, a pesar de su teórico hibridismo entre tradición griega y bárbara, existía la hegemonía de una elite griega que copaba los grandes puestos administrativos frente a la población autóctona (Walbank, 1985), en Cartago encontramos a una aristocracia que, de manera autónoma, introduce aquellos aspectos que más le interesan de la cultura extranjera. Es decir, la tradición fenicia no solo no es sustituida, sino que convive perfectamente con las nuevas costumbres importadas del mundo helenístico. Un buen ejemplo es la religión, ya que tenemos constancia de que el tributo ofrecido 
al santuario de Melqart en Tiro continuó incluso tras la conquista macedónica (DS., XX, 14), siendo aceptada la iconografía sincrética del dios Melqart/Heracles (Jourdain-Annequin, 1992).

Además del factor aristocrático, jugaron un papel importante los contactos previos con espacios como Sicilia y Egipto. El caso siciliano, comentado previamente, fue el más intenso, permitió la introducción de cultos locales como el de Koré que tuvo una gran representación en la iconografía numismática (Alexandropoulos, 2002). Las relaciones con Egipto eran herencia de los intensos lazos comerciales que Cartago había desempeñado con el país del Nilo, manifestado a través de la importación de amuletos y escarabeos (Lancel, 1994). El advenimiento de la dinastía ptolemaica dio paso a una frontera directa a raíz de la anexión de Cirene (Mederos Martín, 2005), esta proximidad geográfica permitió que se canalizase un intenso trasvase cultural, cuya consecuencia fue la introducción de una arquitectura de carácter monumental (Prados Martínez, 2004).

\subsection{La transformación del ejército cartaginés}

Tras dedicar gran parte de nuestro discurso a unas digresiones en relación con la importancia simbólica del elefante en el Mediterráneo de los siglos IV-III a. C. y la problemática concepción del helenismo púnico, pasamos al asunto central: la introducción del elefante en Cartago. Para ello, comenzaremos con una breve noción acerca de la inclusión en los ejércitos cartagineses de este elemento táctico griego.

Los enfrentamientos militares en Sicilia contra Pirro de Epiro debieron de ser el antecedente directo (Scullard 1974), dado que las fuentes presentan un silencio, siendo la primera mención del empleo de elefantes por Cartago en la Primera Guerra Púnica (Plb., I, 18). Una posible solución a este vacío espaciotemporal, a nuestro juicio, es que en la década del 270 a. C. los cartagineses comienzan a hacer acopio de elefantes sirviéndose de las relaciones comerciales y diplomáticas que tenían con los caudillos norteafricanos (Gozalbes Cravioto, 1988). Sin embargo, a diferencia de los reyes helenísticos, en Cartago no había tradición en el uso de los elefantes, por lo cual su efectividad como arma quedaba reducida sensiblemente, aunque se especula que desde Egipto pudieron llegar técnicos que ayudasen con el adiestramiento (Gowers y Scullard, 1950).

En este escenario entró en escena una de las figuras clave del cambio de paradigma en la guerra cartaginesa, el lacedemonio Jantipo. Este soldado mercenario de origen helénico recibió la confianza de Cartago para reorientar la guerra contra los romanos, entre otros aspectos, porque se le consideraba un general experto, que probablemente había sido testigo de la actuación de los elefantes de Pirro en el Peloponeso (Kistler, 2007). Las "reformas" militares emprendidas por Jantipo dieron un peso capital a la caballería y a los elefantes (Griffith, 1935), lo cual convirtió al ejército cartaginés, desde un punto de vista táctico, en una armada helenística (Modanez, 2012). Sus postulados serán perfeccionados por los Bárquidas durante su gobierno de lberia.

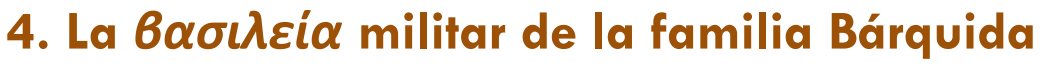

Llegamos a nuestro último bloque, que hemos considerado encabezar con un vocablo griego

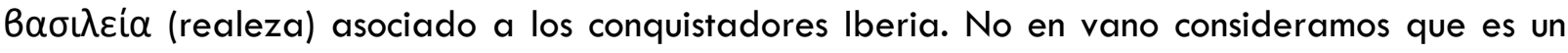
término adecuado al ir seguido del adjetivo "militar", dado que la a menudo calificada como 
"Iberia helenística" debe ser entendida en todo momento desde una adaptación de las lógicas del poder real heleno a partir de la vía castrense. Este complejo proceso, en el que hay que tener en cuenta muchos factores, se gesta bajo los dos primeros gobernadores/comandantes en jefe de la lberia púnica: Amílcar y Asdrúbal, especialmente bajo el segundo, ya que es el ideólogo de la sustitución de la iconografía tradicional fenicia por la helenística, entre la que se incluye el elefante. En lugar de hacer una crónica política de este período, dado que no procede, nos introduciremos directamente en la cuestión iconográfica, dado que esa temática ha sido tratada de forma eficiente por otros profesionales (Bendala Galán, 2015).

\subsection{La imagen de Asdrúbal como rey helenístico en las fuentes}

A pesar de su breve gobierno (228-221 a. C.), la figura de Asdrúbal despertó un gran interés por los historiadores grecorromanos, solamente superada por la de sucesor, Aníbal, cuyas gestas militares lo elevaron hasta la inmortalidad. Sin embargo, Asdrúbal es presentado como un personaje moralmente cuestionable desde la óptica grecorromana, dado que pretendió acabar con el sistema republicano cartaginés e instaurar una monarquía, según Polibio (III, 8):

El historiador romano Fabio afirma también que la ambición y el afán de poder de Asdrúbal fueron, junto a la afrenta saguntina, causa de la guerra Anibálica. Pues Asdrúbal, tras haberse hecho con un amplio dominio de los territorios ibéricos, se presentó en Libia para intentar abolir la legalidad y hacer que el régimen cartaginés pasase a ser una monarquía. Pero los notables, que previeron su intento, le opusieron una cerrada defensa de las leyes. Y Asdrúbal, receloso, salió de Libia para, en lo sucesivo, administrar ya a su arbitrio los asuntos de lberia, sin tener en cuenta al senado de Cartago (...).

Este fragmento es preciso, se acusa a Asdrúbal de tratar de dar un golpe de Estado y ante su fracaso se volvió un despótico sátrapa que gobernó de manera autónoma la "provincia" de Iberia. Un villano perfecto. La historiografía actual ha cuestionado la autenticidad de este juicio, dado que Polibio era un claro partidario de los Escipiones, lo cual lo convierte, cuanto menos, en imparcial con respecto a los Bárquidas. No obstante, una reciente interpretación (García Cardiel, 2019) ha relacionado la imagen tiránica de Asdrúbal con la actuación de los prohombres romanos de la República tardía, los cuales tuvieron un papel destacado en Hispania (Abascal Palazón, 1997). Más allá de interesantes comparativos, volvemos a plantear una cuestión: żqué justificación tenía esta imagen de Asdrúbal?

Ferrer Albelda (2011) exponía los siguientes argumentos para negar la existencia de una influencia helenística en el dominio cartaginés de lberia. Destacaremos tres, por ser, a nuestro juicio, los más relevantes. Un primer aspecto sería la naturaleza del poder ostentado, dado que los distintos gobernantes, aunque proclamados por el ejército a la manera helenística (Plu., Demetr, XVIII; D.S., XXV, 10), fueron ratificados por el Senado de Cartago. Aunque en este caso

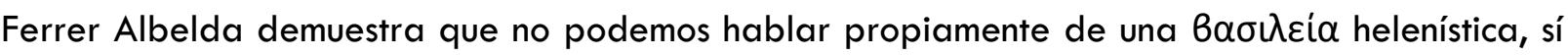
que es cierto que la base del poder de los Bárquidas era su control sobre el ejército, que es una de las cualidades arquetípicas del soberano helenístico (Molina Marín, 2014).

El segundo aspecto es el urbanismo de inspiración helenística de las nuevas fundaciones. Tomaremos un ejemplo práctico, la ciudad de Qart Hadasht. La fundación de Asdrúbal, aunque a diferencia de las ciudades de nueva planta del Próximo Oriente, por poner un ejemplo, no contaba con los edificios típicos de la ciudad griega, caso del gimnasio o el teatro (Kosmin, 2014), 
fue organizada arquitectónicamente, y así lo ha demostrado la arqueología (Noguera Celdrán y Madrid Balanza, 2014) a la manera helenística, especialmente gracias a su sistema defensivo basado en murallas de casamatas.

En tercer lugar, abordaremos la problemática numismática. Esta fuente es, o al menos así lo consideramos, el más vivo testimonio del gobierno Bárquida, dado que refleja su concepción del poder. Independientemente de que nos posicionemos en contra de la retratística, a partir del hecho de que en la tradición fenicia se evitaban las representaciones humanas (Ferrer Albelda, 2011 ), o a favor, basándonos en el uso de atributos propios del retrato helenístico como la tainía (García-Bellido, 2013), lo cierto es que, mediante la combinación de atributos de la realeza griega y símbolos religiosos, los Bárquidas, y en particular Asdrúbal, invitaban a la ambigüedad (Barceló, 2017).

De las tres series helenísticas atribuidas a Asdrúbal hemos de destacar las acuñaciones que han sido identificadas con Amílcar y Aníbal, dado que son las únicas acuñaciones del Mediterráneo occidental que incluyen elefantes en su iconografía, salvo el caso de Agatocles, hasta el final de la Segunda Guerra Púnica. En consonancia con las fuentes (Liv., XXI, 4), el uso de esta retratística individualizada de los miembros de la "dinastía" por parte de Asdrúbal puede ser interpretado como un recurso que busca afianzar su parentesco con Amílcar y Aníbal, los cuales gozaban del favor del ejército, y tener un contrapeso ante la facción de Hannón en Cartago, sus principales rivales políticos (Martínez Hahnmuller, 2016).
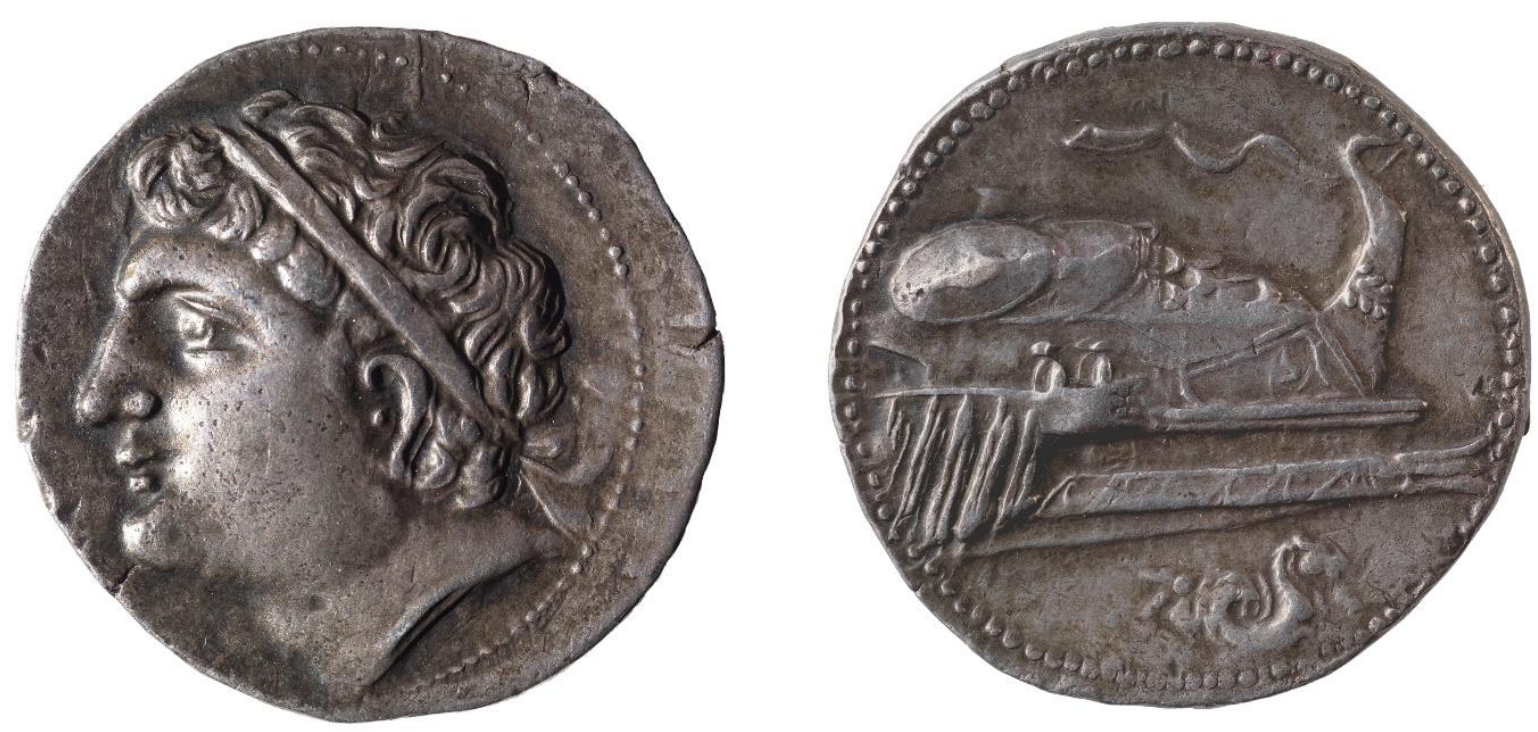

Figura 6. Shekel hispanocartaginés de plata (14,68 g.). A) El anverso muestra una efigie masculina imberbe con tainía (¿Asdrúbal?). B) El reverso una proa de nave de guerra con un tritón en la parte inferior. Siglo III a. C. Fuente: Museo del Prado (O001817).

Un buen ejemplo de ello es la Figura 6. En el anverso se representa una efigie masculina imberbe, en la que destaca su cabello en forma de anastole y el uso de la tainía. La orientación de la mirada hacia el cielo ha sido interpretado como un símbolo de que el representado estaba vivo (García-Bellido, 2013). El reverso muestra la proa de una trirreme sobre la que aparece una hilera de escudos. En la iconografía helenística, la representación de la proa suele ir asociada a la conmemoración de triunfos en batallas navales (Dahmen, 2007), aunque si aceptamos que se trata de una representación de Asdrúbal, es posible que sea una alusión a su condición de triarca 
bajo el mando de Amílcar (Bendala Galán, 2015). La inclusión del hipocampo, criatura mitológica, es posible que sea una alusión al mar. Ambas figuras van flanqueadas por grafilas.

\subsection{Particularidades de los elefantes cartagineses}

Las series denominadas "hercúleas" de Asdrúbal presentan, tal y como hemos comentado, en sus reversos elefantes. La riqueza de estas fuentes no tiene parangón, dado que son un vivo testimonio de los elefantes empleados por los cartagineses, pudiendo abordar los elementos más destacados de estas especies. En las acuñaciones "barbadas" (Figura 7) se representa a un elefante africano de bosque (Loxodonta Africana Cyclotis), sobre el cual va montado un cornaca que le dirige con una aguijada, en este caso no se incluye la torre. En las series "imberbes" (Figura 8) se vuelve a representar al elefante africano, pero esta se vez sin su cornaca. Identificamos a la especie gracias a su fisionomía, orejas de gran pabellón, lóbulo redondeado, marcada depresión en el centro de la espalda ("silla de montar"), cabeza alta y trompa anillada (Lancel, 1997).
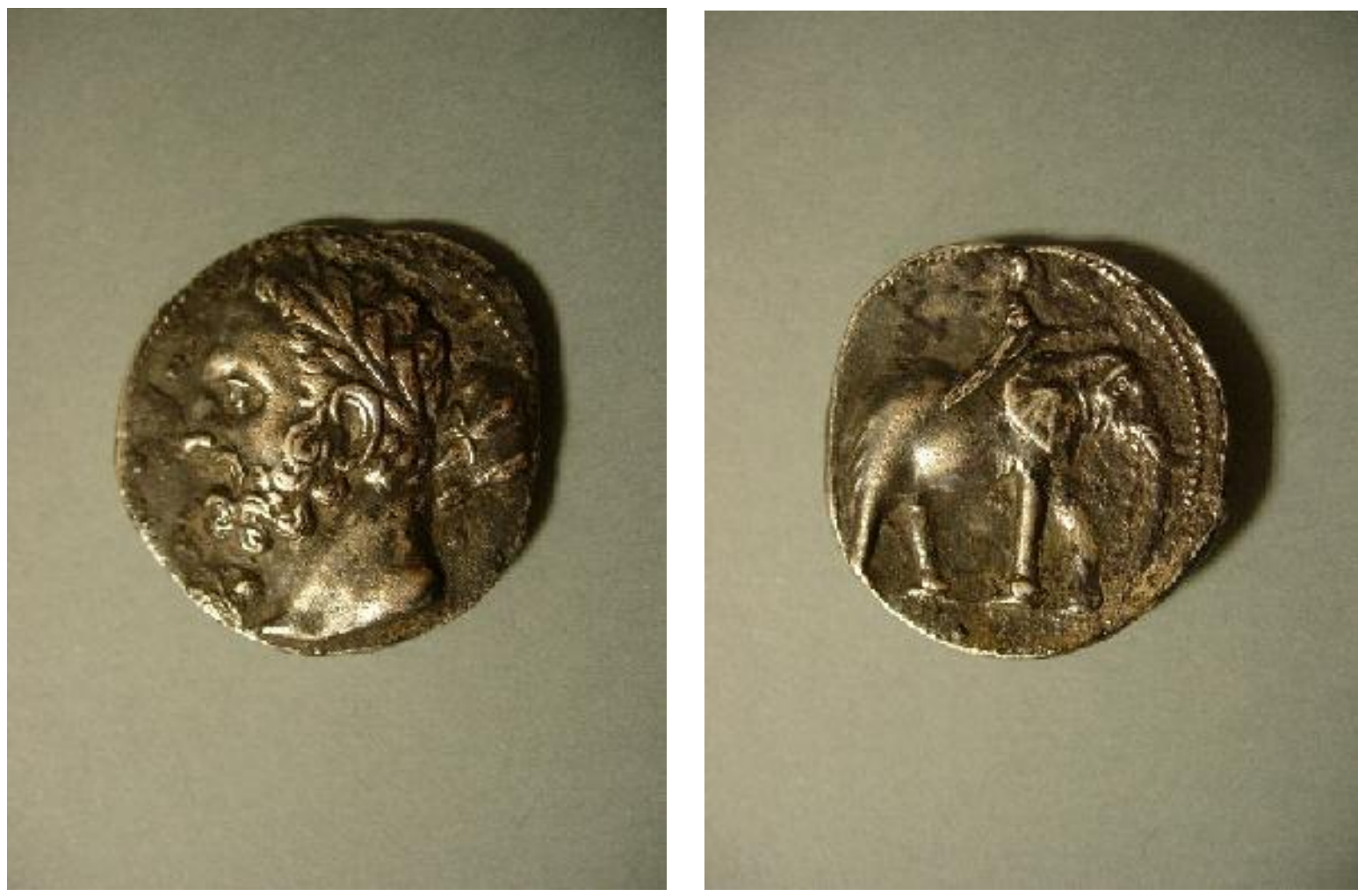

Figura 7. Dishekel de plata (14,20 g). A) El anverso representa una efigie masculina barbada con clava (¿Amílcar?). B) El reverso muestra un elefante de bosque africano con su cornaca. S. III a. C. Fuente: Museo de Jaén (DJ/NU06688).

El anverso de la Figura 7 representa una efigie masculina barbada, coronada por una palma. Junto al rostro se añade una clava, símbolo de fuerza asociado con el dios Melqart/Heracles. Aunque la inclusión de este símbolo sacro pueda inducir a primera vista a pensar que nos encontramos ante una deidad, no debemos olvidar, tal y como se expuso líneas arriba, que, tras la muerte de Alejandro, este solía ser representado con atributos propios de los dioses. Por ello, siguiendo la premisa de la ambigüedad (Barceló, 2017), creemos que se trata de un retrato de Amílcar Barca. Por otra parte, el reverso muestra a un elefante conducido por un cornaca. A diferencia de las Figuras 4 y 5, no presenta rasgos asiáticos, sino más bien africanos, por lo cual podríamos afirmar que los cartagineses se servirían de cornacas autóctonos del Norte de África. 
El hecho de que no se represente una torre, al igual que ocurre con la Figura 8, confirma que nos hallamos ante un elefante de bosque, cuya morfología impedía su uso (Charles y Rhodan, 2007).

Como vemos, estas acuñaciones recuperan la iconografía seléucida del elefante adaptándola a su cotidianeidad. Sin embargo, en este caso, el objetivo no era el exaltar la figura del soberano, o en este caso del general, sino más bien servir como advertencia, dado que el elefante, además de ser un arma excepcional en tiempos de guerra, también era un instrumento utilizado para castigar a los insubordinados. Una vez más, recurrimos a la exposición directa de la fuente escrita, aunque en este caso compararemos a dos autores diferentes, Quinto Curcio y Polibio:

Pérdicas, al verlos paralizados y en sus manos, apartó, sacándolos de entre las filas de la infantería, a los 300, más o menos, que habían seguido a Meleagro cuando éste se había marchado violentamente de la asamblea (la primera que se había celebrado tras la muerte de Alejandro) y, a la vista de todo el ejército, los arrojó a los elefantes; todos fueron pisoteados por los animales sin que Filipo ni lo prohibiera ni lo autorizara: estaba claro que él sólo reivindicaría como propio aquello que tuviera éxito (Curt., $X, 9,18$ ).

(...) pero cuando los libios se enteraron de la captura de sus caudillos, como no conocían el tratado, estimaron que estos habían sido traicionados, motivo que les llevó a tomar las armas. Amílcar entonces los rodeó con todos los elefantes y el resto de sus fuerzas y les dio muerte a todos. -Eran más de cuarenta mil- (...) (Plb., l, 85).
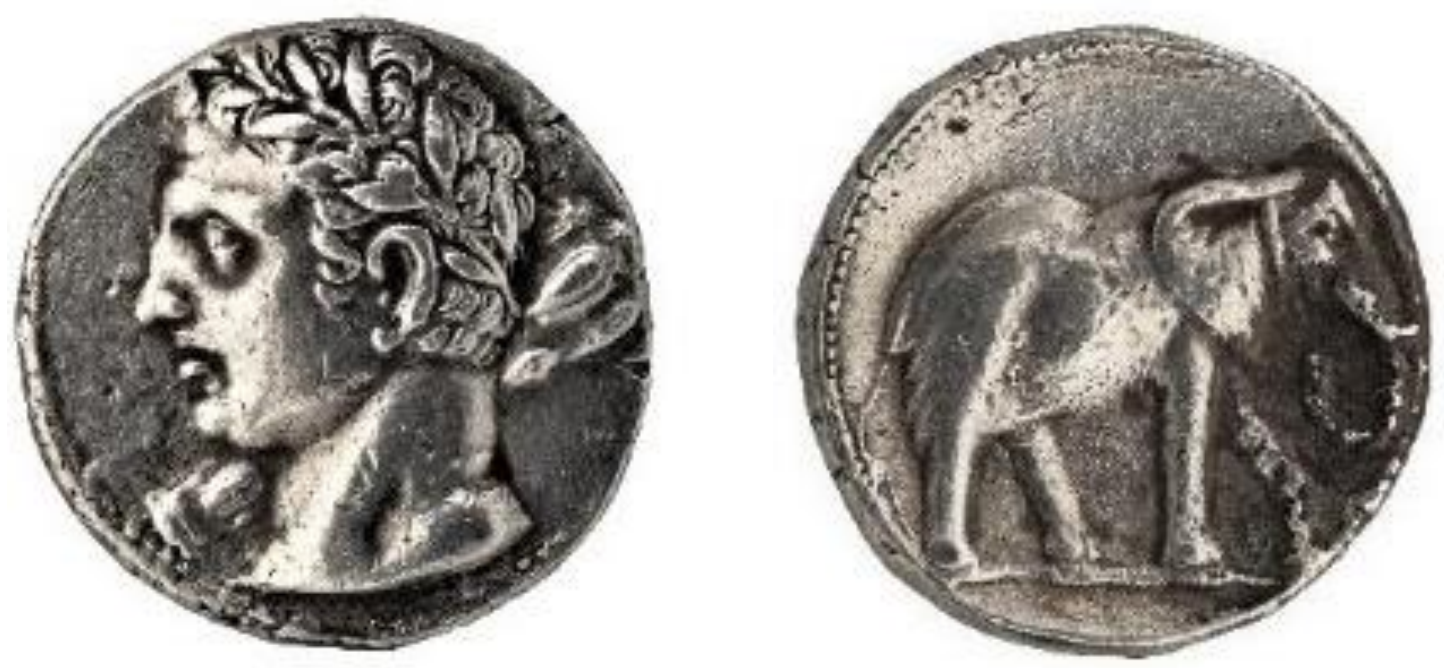

Figura 8. Trishekel de plata $(22,22 \mathrm{~g})$. A) El anverso muestra una efigie masculina imberbe con clava (¿Aníbale). B) El reverso un elefante africano de bosque. Siglo III a. C. Fuente: Museo Arqueológico Nacional (1993/67/1551).

El primer texto nos remite a la represión del motín estallado tras la crisis sucesoria a la muerte de Alejandro III de Macedonia en Babilonia (323 a. C.), el segundo caso describe la batalla de la Sierra (239 a. C.), en la que Amílcar acaba con los mercenarios rebeldes. A pesar de la distancia espaciotemporal, ambos casos convergen en un factor común: el elefante es utilizado para someter a los insurgentes. Es por ello por lo que consideramos que la inclusión del elefante por parte de Asdrúbal en estas series era una forma de transmitir el mensaje a sus soldados, mercenarios mayormente, de que no se iban a tolerar motines. Tengamos en cuenta que venimos de una guerra despiadada que había supuesto un duro golpe para la región norteafricana, era necesario mantener un gobierno firme desde la "provincia". 


\section{Reflexiones finales}

A lo largo del presente trabajo hemos tratado de ofrecer un poco de luz acerca del uso de la iconografía del elefante en las acuñaciones hispanocartaginesas, a la vez que tratábamos el espinoso tema de la helenización de Cartago.

Realizadas las aportaciones previas, consideramos que la helenización de Cartago, a nivel general, y de los Bárquidas, a nivel particular, responde a cuestiones diferentes, dado que en la metrópoli africana el influjo griego sigue los cauces culturales previos a través de dos espacios en los que se da una gran interacción militar y comercial. No obstante, esta helenización debe ser matizada, en el sentido de que se manifiesta en el gusto de una elite por aprender griego, las reformas del ejército y el desarrollo arquitectónico, lo cual no debe hacernos olvidar el factor fenicio, que nunca llegó a ser sustituido por el griego.

El citado trabajo de Bonnet (2014) es clave en este aspecto, desde nuestro punto de vista, en el sentido de que asistimos a un cambio dentro de la mentalidad del historiador. Cartago es un espacio muy rico en el que confluyen multitud de cambios a lo largo de su historia, que la configuran como un sujeto de estudio histórico capital en la Antigüedad, a pesar de toda la serie de tópicos heredados de los siglos pasados en los que se le consideraba como un pequeño oasis del orientalismo. Precisamente, su riqueza reside en su papel como puente en Oriente y Occidente, lo cual la convierte en un catalizador de la cultura griega hacía el resto de los espacios de África (Prados Martínez, 2004).

El caso Bárquida es más complejo de analizar. Nuestras percepciones también se encuentran distorsionadas como consecuencia de esa metamorfosis generada por la historiografía, la cual aceptaba sin juicio crítico las fuentes grecorromanas, que ha optada por convertirlos en unos "sátrapas de Occidente", tal y como hemos expuesto con la figura de Asdrúbal. Su política desarrollada en lberia debe de ser analizada desde otras ópticas, ya que se sirven de la

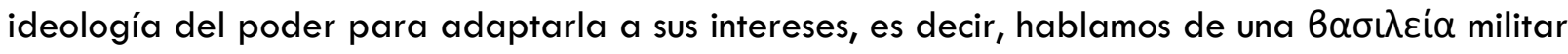
que se ampara en el ejército como instrumento de poder. Es por ello, que no estamos de acuerdo con los planteamientos que niegan los rasgos helenísticos en lberia, aunque tampoco lo estamos con esa idea de "monarquía Bárquida", preferimos el mencionado término de "helenistización", dado que alude a una fase tardía del helenismo en la que tienen cabida las actuaciones de estos personajes. El elefante es una de estas adaptaciones, cuyo cometido, a diferencia del caso griego, es servir de elemento coercitivo en un territorio extranjero ante una soldadesca multiétnica que solamente era leal a su señor si este triunfaba y le garantizaba su soldada.

Las interpretaciones y los análisis generados a lo largo del proceso de gestación del presente artículo nos inclinan a pensar que la iconografía del elefante en las series hispanocartaginesas es una evidencia de peso para comenzar a abordar otros paradigmas en relación con el helenismo en Occidente desde nuevas perspectivas. Es precipitado afirmar con rotundidad que nuestros personajes se consideraban por encima del sistema institucional de su ciudad de origen, cosa que difícilmente podremos saber algún día. Lo cierto es, sin embargo, que lejos de apropiarse de los modelos representativos de los reyes griegos de Oriente, adaptan el mensaje a su realidad histórica. Debemos dejar de fomentar discursos de alteridad sobre el mundo púnico, hay más mundo más allá de la Segunda Guerra Púnica. 


\section{Bibliografía}

Abascal Palazón, J. M. (1997). La ciudad de Carthago Nova: La documentación epigráfica. Murcia: Universidad de Murcia.

Alexandropoulos, J. (2002). Les monnaies de l'Afrique antique: 400 av. J.-C.-40 ap. J.-C. Presses Universitaires du Mirail: Toulouse.

Alonso Troncoso, V. (2013). The Diadochi and the zoology of kingship: The Elephants. En V. Alonso Troncoso y E. Anson (coords.), After Alexander: the time of the Diadochi (323-281 bc) (pp. 254-270). Oxford: Oxbow Books.

Barceló, P. (2017). Aníbal de Cartago. Madrid: Alianza Editorial.

Barceló, P. (2019). La Guerras Púnicas. Madrid: Síntesis.

Bendala Galán, M. (2015). "Hijos del rayo". El dominio cartaginés en Hispania. Madrid: Trébede.

Berthelot, A. (1936). Questions hannibaliques: les éléphants d'Hannibal au Mont-Cenis. Revue des Études Anciennes, 38(1), 35-38.

Blázquez, J. M. (1976). Consideraciones históricas en torno a los supuestos retratos bárquidas en las monedas cartaginesas. Numisma, XXVI, 39-48.

Bonnet, C. (2014). Phoenician identities in Hellenistic times: strategies and negotiations. En J. C. Quinn y N. Vella (eds.) The Punic Mediterranean. Identities and Identification from Phoenician Settlement to Roman Rule (pp.282-298). Cambridge: Cambridge University Press.

Bosworth, B. (2002). The Legacy of Alexander. Politics, Warfare, and Propaganda under the Successors. Oxford: Oxford University Press.

Charles, M. B. y Rhodan, P. (2007). "Magister Elephantorum": A reappraisal of Hannibal's Use of Elephants. The classical World, 100(4), 363-389.

Dahmen, K. (2007). The legacy of Alexander the Great on Greek and Roman coins. London-New York: Routledge.

Erickson, K. (2019). The Early Seleukids, their Gods and their Coins. New York: Routledge.

Ferrer Albelda, E. (2002-2003). Gloria y ruina de la lberia Cartaginesa. Imágenes del poder en la historiografía española, CuPAUAM, 28-29, 7-21.

Ferrer Albelda, E. (2011). Rasgos ideológicos helenísticos en la política helenística de los Barca. En Cortés Copete, J. M., Muñiz Grijalvo, E. y Gordillo Hervás, R. (eds.), Grecia ante los Imperios. $V$ reunión de historiadores del mundo griego (pp. 305-317). Sevilla: Universidad de Sevilla.

García-Bellido, M. P. (2013). El nacimiento del retrato monetario en Occidente: la familia Bárquida". En M. Bendala Galán, M. Pérez Ruiz y I. Escobar (coords.), Fragor Hannibalis. Aníbal en Hispania (pp. 174-207). Madrid: Comunidad de Madrid, Museo Arqueológico Regional.

García-Bellido, M. P. (2019). Las monedas de los Barca. Desperta Ferro. La Segunda Guerra Púnica (I). Aníbal en Hispania, LIII, 46-49.

García Cardiel, J. (2019). Asdrúbal. Un estadista en provincias. Desperta Ferro. La Segunda Guerra Púnica (I). Aníbal en Hispania, LIII, 24-30. 
García Coca, V. (2012). La ciudad de Aníbal. Urbanismo y arquitectura de la Cartago helenística. En S. Remedios, F. Prados y J. Bermejo (eds.), Aníbal de Cartago. Historia y mito (pp.71-99). Madrid: Polifemo.

Goukowsky, P. (1981). Essay sur les origines du mythe de Alexandre. (336-270 a.C.). II Alexandre et Dionysos. Nancy: Université de Nancy.

González Wagner, C. (1999). Los Bárquidas y la conquista de la Península Ibérica. Gerión, 17, 265-294.

Gonzalbes Cravioto, E. (1988). Los elefantes de Septem Frates. Cuadernos del archivo municipal de Ceuta, 2, 3-12.

Griffth, G.T. (1935). The Mercenaries of the Hellenistic Worlds. Chicago: Ares Publishers.

Gowers, W. y Scullard, H. H. (1950). Hannibal's elephants again. The Numismatic Chronicle and Journal of the Royal Numismatic Society, 10, 271-283.

Hoyos, D. (2010). The Carthaginians. New York: Routledge.

Jehasse, J. y Jehasse, L. (1973). La nécropole préromaine d'Aléria (1960-1968). Paris: Centre National de la Recherche Scientifique.

Jiménez Vialás, H. (2012). Aníbal en la cultura europea. De Dante a Flaubert. (ss. XIV-XIX). En S. Remedios, F. Prados, F. y J. Bermejo (eds.). Aníbal de Cartago. Historia y mito (pp. 493517). Madrid: Polifemo.

Jourdain-Annequin, C. (1992). Héraclès-Melqart à Amrith. Recherches iconographiques. Contribution a l'étude d'un syncrétisme. Bibliothèque Archéologique et Historique, CXLII. Paris: Institut Français du Proche-Orient Beyrouth-Damas-Amman.

Kistler, J. (2007). War Elephants. Connecticut: University of Nebraska Press.

King, C. (2018). Ancient Macedonia. New York: Routledge.

Kosmin, P. (2014). The land of the elephant kings. Space, Territory, and Ideology in the Seleucid Empire. Cambridge: Harvard University Press.

Lancel, S. (1994). Cartago. Barcelona: Crítica.

Lancel, S. (1997). Aníbal de Cartago. Barcelona: Crítica.

Laugher, C. (2000). Agatocle. Da capoparte a monarca fondatore di un regno tra Cartagine e i Diadochi. Mesina: Pelorias.

Martínez Hahnmuller, V. (2016). Una historia del Mediterráneo Occidental. La lucha por el poder en Cartago durante la segunda mitad del siglo III a.C. Gerión, XXXIV, 127-144.

Mederos Martín, A. (2005). El periplo norteafricano de Ofelas. Gerión, 24, I, 65-84.

Modanez de Sant'Anna, H. (2012). Inovações militares na Cartago helenística, da expedição de Agátocles à invasão romana durante a Primeira Guerra Púnica. Ágora: estudos clássicos em debate, 14, 107-130.

Molina Marín, A. I. (2014). El miedo como arma de dominación: admiración, pavor y victoria en la imagen del rey guerrero en el helenismo inicial. Gladius. Estudios sobre arte militar y vida cultural en oriente y occidente, XXXIV, 95-110. 
Noguera Celdrán, J. M. y Madrid Balanza, M. J. (2014). Carthago Nova: Fases de monumentalización urbana y arquitectónica (siglos III a.C.-III d.C.). Espacio, Tiempo y Forma. Serie I Prehistoria y Arqueología, 7, 13-60.

Pfrommer, M. (1993). Metalwork from the Hellenized East: Catalogue of the Collections. Malibu: The J. Paul Getty Museum.

Prados Martínez, F. (2004). Cartago a la luz de Pharos. Notas sobre la presencia de aspectos arquitectónicos alejandrinos en la arquitectura monumental púnica. Revista di studi fenici, XXXII(2), 57-77.

Purcell, N. (2013). On the significance of East and West in today's 'Hellenistic' history: reflections on symmetrical worlds, reflecting through world symmetries. En J. R. W. Prag y J. C. Quinn (eds.), The Hellenistic West (pp.367-391). Cambridge: Cambridge University Press.

Scullard, H. H. (1974). The elephant in the Greek and Roman world. New York: Cornell University Press.

Lancel, S. (1997). Aníbal de Cartago. Barcelona: Crítica.

López Castro, J. L. (1991). El imperialismo cartaginés y las ciudades fenicias de la Península Ibérica entre los siglos VIIII a.C. Studi di Egittologia e di Antichità Puniche, 9, 87-107.

Thonemann, P. (2016). The Hellenistic Age. Oxford: Oxford University Press.

Trautmann, T. R. (2015). Elephants and Kings. An Environmental History. Chicago: University Chicago Press.

Van Oppen de Ruiter, B. (2019). Monsters of Military Might: Elephants in Hellenistic History and Art. Arts, 8, 1-37.

Villaronga, J. (1973). Las monedas hispano-cartaginesas. Barcelona: Sección Numismática del Círculo Filatélico y Numismático.

Walbank, F. B. (1985). El Mundo Helenístico. Madrid: Taurus.

Whittaker, C.R. (1978). Carthaginian Imperialism in the Fifth and Fourth Centuries. En P. D. A. Garnsey y C. R. Whittaker (eds.), Imperialism in the Ancient World (pp. 59-99). Cambridge: Cambridge University Press.

\section{Fuentes}

Aristóteles. Historia de los animales. Madrid: Akal. 1990. [Edición de José Vara Donado].

Arriano. Anábasis de Alejandro Magno, libros I-III. Madrid: Biblioteca Clásica Gredos. 1982. [Edición de Antonio Guzmán Guerra].

Apiano. Historia Romana, libro III (Guerras Civiles III-V). Madrid: Biblioteca Clásica Gredos. 1985. [Edición de Antonio Sánchez Royo].

Apiano. Historia Romana, libro IX. Madrid: Biblioteca Clásica Gredos. 1980. [Edición de Antonio Sánchez Royo].

Claudio Eliano. Historia de los animales, libros IV-XVI. Madrid: Biblioteca Clásica Gredos. 1984. [Edición de José María Díaz-Regañón López]. 
Cornelio Nepote. Vidas. Madrid: Biblioteca Clásica Gredos. 1985. [Edición de Manuel Segura Moreno].

Diodoro de Sicilia. Biblioteca Histórica, libros I-IIl. Madrid: Biblioteca Clásica Gredos. 2001. [Edición de Francisco Parreu Alasa].

Diodoro de Sicilia. Biblioteca Histórica, libros XVIII-XX. Madrid: Biblioteca Clásica Gredos. 2014. [Edición de Juan Pablo Sánchez].

Diodorus Siculus. Historical Library, books XXI-XXXII. London: Loeb Classical Library. 1980. [Edition of F.R. Walton].

Estrabón. Geografía, libros XV-XVII. Madrid: Biblioteca Clásica Gredos. 2015. [Edición de Juan Luis García Alonso, María Paz de Hoz García-Bellido y Sofía Torallas Tovar].

Floro. Epítome de la Historia de Tito Livio. Madrid: Biblioteca Clásica Gredos. 2000. [Edición de Gregorio Hinojo e Isabel Moreno].

Homero. Himnos homéricos/La Batracomaquía. Madrid: Biblioteca Clásica Gredos. 1976. [Edición de Alberto Bernabé Pajares].

Justino. Epítome de las historias filípicas de Pompeyo Trogo. Madrid: Biblioteca Clásica Gredos. 1995. [Edición de José Castro Sánchez].

Kautilya. The Arthashastra. New York: Penguin Books. 1992. [Edition of L.N. Rangarajan].

Plutarco. Vidas Paralelas, libro IV. Madrid: Biblioteca Clásica Gredos. 2007. [Edición de Juan Manuel Guzmán Herminda y Oscar Martínez García].

Plutarco. Vidas Paralelas, libro VI. Madrid: Biblioteca Clásica Gredos. 2007. [Edición de Jorge Bergua Cavero, Salvador Bueno Morillo y Juan Manuel Guzmán Herminda].

Plutarco. Vidas Paralelas, libro VIl. Madrid: Biblioteca Clásica Gredos. 2007. [Edición de Juan Pablo Sánchez Hernández y Marta González].

Polibio. Historia de Roma. Madrid: Alianza Editorial. 2008. [Edición de José María Candau Morón].

Quinto Curcio Rufo. Historia de Alejandro Magno. Madrid: Biblioteca Clásica Gredos. 1986. [Edición de Francisco Pejenaute Rubio].

Tito Livio. Historia de Roma desde su fundación, libros XXI-XXV. Madrid: Biblioteca Clásica Gredos. 1993. [Edición de José Antonio Villar Vidal]. 


\section{Panta Rei}

PANTA REl es una revista digital de investigación orientada a la Historia y la Didáctica de la Historia. Su principal objetivo es la transmisión del conocimiento científico, dando una oportunidad también a los jóvenes investigadores que quieren abrirse camino en el estudio de las ciencias humanas y sociales. Se compone de estudios originales relacionados con la disciplina histórica así como su didáctica y difusión. Las diferentes secciones que componen la revista son: artículos de investigación, entrevistas a profesionales, recensiones de monografías de actualidad y crónicas de congresos o eventos científicos relevantes.

Todos los artículos publicados son objeto de un proceso de revisión a cargo de un mínimo de dos evaluadores, que se consideran expertos en el ámbito temático del artículo propuesto. Nuestro deseo es poder ofrecer unos contenidos rigurosos, de calidad y de interés.

El CEPOAT (Centro de Estudios del Próximo Oriente y la Antigüedad Tardía de la Universidad de Murcia) es la institución encargada de la coordinación y gestión de la revista, desde donde anualmente se lanzará la convocatoria para aquellos que estén interesados en publicar sus trabajos, siempre relacionados con la Historia y la Didáctica de la Historia.

PANTA REI is a digital journal focused on History and Teaching History. Its main objective is the transmission of scientific knowledge by giving also an opportunity to young researchers who want to make their way in the study of human and social sciences. It is composed by original studies related to History, as well as its didactics and promotion. The different sections of this journal are: research articles, interviews to professionals, recensions on monographs about current issues and reports about congresses or relevant scientific events.

All the articles published are subject to a revision process carried out by a minimum of two reviewers who are considered to be experts in the field of the article proposed. Our wish is to offer rigorous contents with quality and being of interest to the reader.

CEPOAT (Centre of Studies of the Middle East and Late Antiquity of the University of Murcia) is the institution in charge of the coordination and management of this journal. This is the centre from where the call for papers will be launched annually for all the people interested in publishing their papers, always related to History and Teaching History. 


\section{Normas de publicación}

El autor se compromete a enviar trabajos originales, que no se encuentren publicados en otras revistas ni en otros idiomas. Así mismo, el mismo artículo no podrá ser presentado en otras revistas mientras dure el proceso de evaluación.

\section{Envío y presentación de originales}

Las normas de edición y forma de envío de artículos a la revista se pueden consultar en https://revistas.um.es/pantarei/

Para la redacción de los trabajos se tendrá en cuenta el Manual de la American Psychological Association, en su $7 .^{a}$ edición. La extensión máxima de los trabajos será de 25 páginas. La revista acepta originales escritos en español o inglés.

\section{Proceso de valoración y evaluación}

Una vez recibidos los trabajos, la Revista realizará una primera valoración. Si el trabajo enviado se ajusta a las normas de presentación propuestas, la temática es coincidente con la línea editorial de la revista y posee la calidad científica necesaria, será remitido al consejo asesor para una primera evaluación. Si no es así en este primer paso se puede rechazar directamente los documentos que incumplan claramente la línea editorial.

Será el Consejo Asesor quien indique a la revista la originalidad, relevancia, estructura, redacción, aparato bibliográfico, etc. del trabajo enviado y, para ello, se designará a dos revisores expertos externos que evaluarán cada uno de los trabajos, que pueden formar parte (o no) de este Consejo Asesor. La selección de los revisores se ajustará a la temática y características metodológicas del trabajo. El nombre y filiación de los autores serán eliminados del trabajo para su revisión, así como los revisores actuarán de manera anónima y confidencial.

Los revisores deberán rellenar un informe de evaluación que centrará su atención en aspectos tales como características formales, originalidad y novedad de los trabajos, relevancia de las propuestas y los resultados, calidad metodológica y validez científica.

Una vez terminado el proceso se decidirá la aceptación o no de los mismos y su publicación en el número que sea pertinente, así como las modificaciones susceptibles de ser realizadas para su final publicación. Dicha notificación se enviará únicamente por correo electrónico, en un plazo máximo de seis meses. 


\section{Publishing rules}

The author is committed to submit original papers not having been published in other reviews or in other languages. In this way, it is not allowed for the same paper to be presented in other reviews during the evaluation process.

\section{Submission and presentation of originals}

The editing rules and the guidelines for the submission of papers can be consulted at https://revistas.um.es/pantarei/

The seventh edition of the Manual of the American Psychological Association will be taken into account for the writing of the papers. The length of the submitted papers will not exceed the 25 pages. The journal accepts originals written in Spanish or English.

\section{Examination and assessment process}

The Journal will submit the papers to a first examination once received. If the paper follows the presentation guidelines, the subject agrees with the editorial line of this journal, and possess the scientific quality required, it will be sent to the advisory council for a first assessment. If not, the documents which clearly fail to complete the editorial line may be rejected straightaway in this first step.

The Advisory Council will indicate the originality, relevance, structure, writing, bibliography, etc. of the text to the journal; for this purpose, two outside experts will be designated to review the papers; these experts can be (or not) part of this Advisory Council. The selection of the experts will adjust to the subject and methodological characteristics of the paper. Name and affiliation of the author will be eliminated from the text for its review, in this way experts will act anonymously and confidentially.

The experts will fill out an assessment report which will focus on aspects such as formal characteristics, originality and novelty of the papers, relevance and results of the proposal, methodological quality and scientific validity.

Once the process is finished, the acceptance or not of the papers and its publication in the corresponding edition will be decided, as well as the modifications that may be done for its final publication. This notification will be sent by email within 6 months maximum. 


\section{cepoAt edit.um}

